\title{
RELAÇÕES RACIAIS NA COMUNIDADE QUILOMBOLA MACACO BRANCO: RESISTÊNCIA NEGRA EM MEIO A CONFLITOS TERRITORIAIS E ONTOLÓGICOS
}

\author{
Dirce Cristina de Christo (1) $\square$
}

Universidade Federal do Rio Grande do Sul I Porto Alegre - RS - Brasil

José Carlos Gomes dos Anjos (1) 


\section{RESUMO}

Este artigo refere-se a uma etnografia feita na comunidade quilombola Macaco Branco, localizada no município de Portão, Rio Grande do Sul, Brasil. O objetivo da pesquisa foi compreender de que forma as relações raciais estão conectadas com os conflitos territoriais que marcam a história da comunidade. Partindo de uma contextualização do quilombo dentro do paradigma da modernidade colonial, identifica-se uma ontologia distinta dentro da comunidade, que não separa natureza e cultura, mantendo um modo coletivo de estar no território, que resiste historicamente à invisibilização imposta por uma sociedade racista.

Palavras-chave: comunidade quilombola; racismo; território.

\section{RACE RELATIONS IN THE MACACO BRANCO QUILOMBOLA COMMUNITY: BLACK RESISTANCE AMID TERRITORIAL AND ONTOLOGICAL CONFLICTS}

\section{ABSTRACT}

This paper refers to an ethnography made in the Macaco Branco quilombola community, located in the city of Portão, Rio Grande do Sul, Brazil. The objective of the research was to understand how race relations are connected with territorial conflicts that mark the history of the community. Starting from a contextualization of the quilombo within the paradigm of colonial modernity, a distinct ontology is identified within the community, which does not separate nature and culture, maintaining a collective way of being in the territory, which has historically resisted the invisibility imposed by a racist society.

Keywords: Quilombola community;

\section{RELACIONES RACIALES EN LA COMUNIDAD QUILOMBOLA MACACO BRANCO: RESISTENCIA NEGRA EN MEDIO DE CONFLICTOS TERRITORIALES Y ONTOLÓGICOS}

Este trabajo hace referencia a una etnografía realizada en la comunidad quilombola Macaco Branco, ubicada en el municipio de Portão, Rio Grande do Sul, Brasil. El objetivo de la investigación es comprender cómo las relaciones raciales están vinculadas a conflictos territoriales que marcan la historia de la comunidad. Partiendo de una contextualización del quilombo dentro del paradigma de la modernidad colonial, se identifica una ontología distinta dentro de la comunidad, que no separa la naturaleza y la cultura, manteniendo una forma colectiva de estar en el territorio, que históricamente ha resistido la invisibilidad impuesta por una sociedad racista.

Palabras clave: comunidad quilombola; 


\section{INTRODUÇÃ̃ ${ }^{1}$}

As minhas relações com a comunidade quilombola Macaco Branco começaram em 2015, quando participei de um projeto de extensão universitária e pude acompanhar a equipe do Instituto de Colonização e Reforma Agrária (INCRA), que realizava entrevistas para a elaboração do relatório históricoantropológico que embasa o processo de regularização fundiária das comunidades remanescentes de quilombo. A partir dos vínculos criados com algumas famílias nessa época, pude retornar à comunidade em 2017, para consultá-las quanto à possibilidade de realização da pesquisa que desenvolvi durante o Mestrado, o que se efetivou no ano seguinte. Como é próprio do método etnográfico, a presença em campo trouxe à tona diversos temas, mas o foco aqui é dado nas relações raciais presentes no território, descritas a partir da escuta de narrativas dos quilombolas e também da observação participante realizada ao longo dos meses em que estive na comunidade.

O objetivo central deste artigo é entender como se dão as relações raciais na comunidade e como elas estão ligadas aos conflitos territoriais que atravessam o quilombo neste momento, procurando compreender as distintas concepções ontológicas presentes nessa disputa entre uma comunidade tradicional e o projeto oficial de sociedade no Brasil.

O artigo está dividido nos seguintes tópicos: primeiramente, é feita uma aproximação com teorias que nos embasam para discutir essa problemática; em seguida, há uma contextualização histórica do quilombo, na qual eclode a invisibilização das comunidades tradicionais e seu apagamento nas narrativas oficiais; na sequência, são descritas as relações raciais no território do Macaco Branco, marcado pela presença da imigração alemã na região; após isso, é feita a descrição dos conflitos territoriais que figuram em meio aos conflitos raciais; por fim, são feitas considerações sobre a diferença de ontologias que pode ser vista nesses conflitos e sobre os potenciais que o modo de vida quilombola apresenta neste momento de crise ambiental planetária, assim como são apontados caminhos para investigações futuras.

1 Este artigo é resultante de uma pesquisa realizada pela autora no âmbito do Mestrado em Desenvolvimento Rural, da Universidade Federal do Rio Grande do Sul (Christo 2018), orientada pelo coautor deste trabalho. A pesquisa foi realizada a partir do método etnográfico, por meio de trabalho de campo efetuado em períodos intermitentes, entre fevereiro e julho de 2018, tendo como espaço e foco o quilombo do Macaco Branco, situado no município de Portão, no Rio Grande do Sul. Em alguns momentos, ao tratar de descrições etnográficas, o texto é escrito em primeira pessoa, denotando relatos da primeira autora, pois foi quem realizou o trabalho de campo. Não obstante, o texto como um todo se faz em coautoria, uma vez que os dados etnográficos foram discutidos com o coautor no processo da pesquisa, sendo as ideias aqui presentes resultantes de um esforço conjunto de articulação. 


\section{APORTES TEÓRICOS}

As comunidades tradicionais estão na raiz da conformação dos territórios brasileiros, mas começaram a ganhar evidência política a partir da Constituição de 1988, que lhes assegura direitos. Comunidades indígenas e quilombolas são nomeadas neste momento, e depois foram se afirmando outras identidades tradicionais, como os ribeirinhos, as quebradeiras de coco e os pescadores artesanais. Estas populações se caracterizam por viver "em estreita relação com o ambiente natural, dependendo de seus recursos naturais para a sua reprodução sociocultural, por meio de atividades de baixo impacto ambiental" (Santilli 2002:2). Estas sociedades trazem conhecimentos tradicionais produzidos coletivamente e transmitidos através da oralidade, os quais sustentam seus modos de vida.

Em 2007, foi instituída a Política Nacional de Desenvolvimento Sustentável dos Povos e Comunidades Tradicionais, construída com a participação de membros de comunidades de diversas partes do país. O texto define povos e comunidades tradicionais como

[...] grupos culturalmente diferenciados e que se reconhecem como tais, que possuem formas próprias de organização social, que ocupam e usam territórios e recursos naturais como condição para sua reprodução cultural, social, religiosa, ancestral e econômica, utilizando conhecimentos, inovações e práticas gerados e transmitidos pela tradição [...] (Brasil 2007).
Foram definidos também os territórios tradicionais como "[...] os espaços necessários a reprodução cultural, social e econômica dos povos e comunidades tradicionais, sejam eles utilizados de forma permanente ou temporária” (Brasil 2007).

Alfredo Wagner de Almeida chama atenção para o fato de que "[...] a noção de 'tradicional' não se reduz à história, nem aos laços primordiais que amparam unidades afetivas, e incorpora as identidades coletivas redefinidas situacionalmente em uma mobilização continuada" (Almeida 2008:30). Isso se expressa na definição de quilombo, que vem absorvendo novos significados, pois, mesmo que tenha um passado vinculado às resistências negras durante o processo escravocrata, as formas de vida das comunidades legatárias dessa história transformaram-se com o correr do tempo e, com isso, também se reconfiguram as identidades dos grupos.

Como afirmam Silva \& Bittencourt Junior (2004), a interferência de segmentos da sociedade nacional ou do Estado sobre grupos étnicos minoritários pode estimular processos de ocultação ou de afirmação de sua identidade. Desse modo, a emergência das comunidades quilombolas se dá na década de 1990, a partir de sua enunciação no texto constitucional de 1988. O Ato das Disposições Constitucionais Transitórias determinou que “[...] aos remanescentes das comunidades dos quilombos 
que estejam ocupando suas terras é reconhecida a propriedade definitiva, devendo o Estado emitirlhes os títulos respectivos" (Brasil 2003). Cercado de tensões e disputas, este reconhecimento das terras quilombolas enfrenta desafios por parte de setores da sociedade que colocam sob suspeita o direito de comunidades negras rurais e urbanas receberem a titulação de suas terras (Brustolin 2015). O risco é que tais procedimentos abram precedente para uma reconfiguração do território brasileiro que desmonte o cenário histórico de concentração crescente da propriedade fundiária.

Entender essas lutas quilombolas exige localizálas em um contexto mais amplo para ver o que está em jogo quando temos, de um lado, comunidades que organizam modos de vida capazes de se reproduzir no território habitado e, de outro, a negação de seu direito a este território.

Primeiramente, as lutas das comunidades tradicionais se diferenciam de outros conflitos agrários, por carregarem o componente étnicoracial. Com o acontecimento político quilombola, explodem os conflitos raciais até então silenciados, vindo à tona "[...] um conjunto de pequenas lutas políticas, até aqui tornadas invisíveis pelo racismo, mas que permitiram a uma série de territórios negros resistir à escravidão e aos processos racistas de expropriação pós-escravidão” (Anjos 2004:13).

Em segundo lugar, essas lutas expressam um conflito relativo ao modelo de desenvolvimento adotado. Pautado na exploração abusiva dos recursos naturais e na homogeneização social, o projeto capitalista global assume vários nomes ao longo da história da colonialidade na América Latina, mas a lógica de aniquilação dos modos de vida tradicionais invariavelmente permanece. Visando à sua expansão contínua, o capital encontra nas comunidades rurais uma barreira à ampliação do seu alcance. Por outro lado, o avanço incontrolável sobre todas as regiões do planeta acabou nos atirando a todos em uma crise socioambiental de efeitos catastróficos cada vez mais presentes.

Este modelo de desenvolvimento está baseado na racionalidade moderna (Escobar 2015), que erige uma série de divisores fundantes de uma concepção unidirecional do tempo, dividindo os seres humanos em modernos e pré-modernos (Latour 1994). Modernos e pré-modernos conformam um par desses divisores, e o sufixo "pré" decorre do fato de se conceber o alcance do estatuto de modernidade como uma consequência de um avanço, de onde surgem as ideias de progresso e desenvolvimento, entre outras, pautadas na lógica de chegar a uma posição adiante de onde se está. Entram na categoria de pré-modernas todas as sociedades que não compartem da racionalidade moderna europeia. Outros divisores que constituem 
essa ontologia de um ser humano explorador e utilitarista são as separações mente/corpo, cultura/ natureza, razão/emoção, sujeito/objeto. Bruno Latour (1994) afirma que estas separações não se dão por completo, mas são um horizonte de busca da modernidade, e o que se encontra na prática são híbridos, variações entre a separação radical e a união total.

Uma consequência da separação entre cultura e natureza é que o ser humano moderno passa a se enxergar como apartado da natureza que o circunda e o compõe, de modo que ele se vê como sujeito, enquanto a natureza é reduzida a objeto a ser intensamente explorado pelo saber científico. Percebendo-se alheio ao ambiente natural, não restam escrúpulos que possam frear a devastação ecológica, que atualmente chega a um ponto crítico.

Retornando às comunidades tradicionais, é preciso dizer que elas não compactuam com estes valores modernos. Arturo Escobar (2015) identifica um conflito de ontologias: a modernidade prega a existência de uma ontologia absoluta, que não deixa espaço para a coexistência de outras, o que se expressa em séculos de tentativas de aniquilação destas "outras"; as comunidades originárias, por sua vez, nos apresentam ontologias diversas, muitos mundos, em oposição a um Mundo da modernidade. O autor as nomeia como ontologias relacionais, as quais não se baseiam em uma racionalidade dual e nas quais não existe um elemento (humano ou não humano) que seja pré-existente aos outros: a existência de todos está relacionada e depende da existência dos demais elementos.

Jorge Montenegro nos fala também de outras possibilidades epistêmicas:

[...] as racionalidades dos povos originários, das comunidades tradicionais, dos grupos miscigenados trabalham no povoamento e aproveitamento dos territórios que ocupam, com lógicas não diretamente assimiláveis à lógica do capital. Esses espaços imbuídos de outras epistemes nos mostram que há diversidades ainda não totalmente subsumidas na lógica do capital, que se reforçam por conhecimentos e cosmovisões outras que não as ocidentais, modernas, científicas (Montenegro 2012:171).

Arturo Escobar (2015) identifica uma dimensão fundamental nas lutas étnico-territoriais, que também se manifesta nas observações do trabalho de campo basilares para este texto: a defesa da vida. Pautadas em ontologias relacionais, as comunidades vivem em interação com os muitos elementos vivos que compõem os territórios, e a defesa do território é também a defesa da possibilidade de que estes mundos, que transcendem o humano, continuem existindo. $\mathrm{O}$ autor nos diz que

[...] os territórios são espaços-tempos vitais de toda comunidade de homens e mulheres; e não apenas isso, mas é também o espaço-tempo de inter- 
relação com o mundo natural que envolve e é uma parte constitutiva dele. Ou seja, a inter-relação gera cenários de sinergia e complementaridade tanto para o mundo de homens e mulheres quanto para a reprodução do restante dos outros mundos que cercam o mundo humano (Escobar 2015:33, tradução nossa).

O conceito de comunidade é alargado para além dos humanos, considerando as demais formas de vida que habitam o território, e as lutas por território defendem a existência desses mundos relacionais, dessas formas de vida que comportam múltiplas possibilidades epistêmicas e que são suprimidas e deslegitimadas dentro do paradigma da modernidade. Desse modo, os conflitos étnicos e ambientais encontram-se entramados, pois a possibilidade de múltiplas existências étnicas, hoje, se apresenta como importante contribuição às transições ecológicas e à continuidade da vida no planeta. As comunidades tradicionais se apresentam como reservatórios de outros modos de vida, construídos em maior equilíbrio com a natureza.

E é a essa possibilidade de outras formas de relação com a vida que se refere este artigo, trazendo para a discussão os aportes de uma pesquisa de campo localizada em uma comunidade quilombola do Sul do Brasil. Nesse sentido, trago agora uma contextualização histórica sobre a comunidade Macaco Branco, que abre os caminhos para pensar como os conflitos territoriais que a comunidade enfrenta estão relacionados a conflitos raciais, resultantes de sua raiz tradicional calcada em uma ontologia relacional.

\section{PRODUÇÃO INSURGENTE DA LIBERDADE:}

\section{A CRIAÇÃO DO QUILOMBO}

Os registros escritos sobre o quilombo são escassos. Um importante movimento realizado nos últimos anos foi a produção do relatório históricoantropológico, desenvolvido pelo INCRA para fins de regularização fundiária; o texto, entretanto, ainda não foi publicado porque o processo ainda não foi concluído. Tal escassez de informações não é obra do acaso, fazendo parte de um projeto político de invisibilização destas comunidades.

Como aponta Cardoso (2007), em sua pesquisa sobre a escravidão no Vale do Rio Caí, a colonização alemã que se deu na região virou referência histórica, apagando a escravidão e o trabalho de africanos e descendentes no interior do Rio Grande do Sul. Esta invisibilização segue presente, mesmo após o reconhecimento oficial da comunidade como quilombola. Um exemplo é o site oficial da prefeitura de Portão, que, ao relatar uma breve história do município, ignora a presença negra no território, mencionando apenas a origem alemã

No entanto, o documentário "Caminhos da Feitoria do Linho Cânhamo - A trajetória histórica 
do povo negro em São Leopoldo" (Dimppir 2009) mostra que a presença negra na região é anterior à chegada dos imigrantes alemães, em 1824. Já em 1788, um contingente de cerca de oitenta escravizados foi enviado para trabalhar em uma feitoria no município de São Leopoldo². Quando da chegada dos alemães, o número de trabalhadores negros em situação de escravidão já chegava a 321. Ao relatar o povoamento da região, a narrativa oficial, porém, segue restringindo-se à imigração alemã. Ainda assim, os quilombolas são guardiões de suas histórias e as transmitem através da prática ancestral da oralidade. E é a partir da descrição destas narrativas ouvidas durante o trabalho de campo que trago um esboço da história do quilombo e da forma como os moradores vivenciam as relações em meio aos conflitos raciais que, entre outras questões, geram a invisibilidade mencionada.

A comunidade quilombola Macaco Branco está situada no município de Portão, no Rio Grande do Sul, a cerca de cinquenta quilômetros de distância da capital Porto Alegre. Localizase na região norte do município (Figura 1), compreendendo as localidades de Cachoeira, Bom Jardim e Morro do Macaco Branco. No entanto, a delimitação precisa da área quilombola ainda não está disponível, pois encontra-se, desde

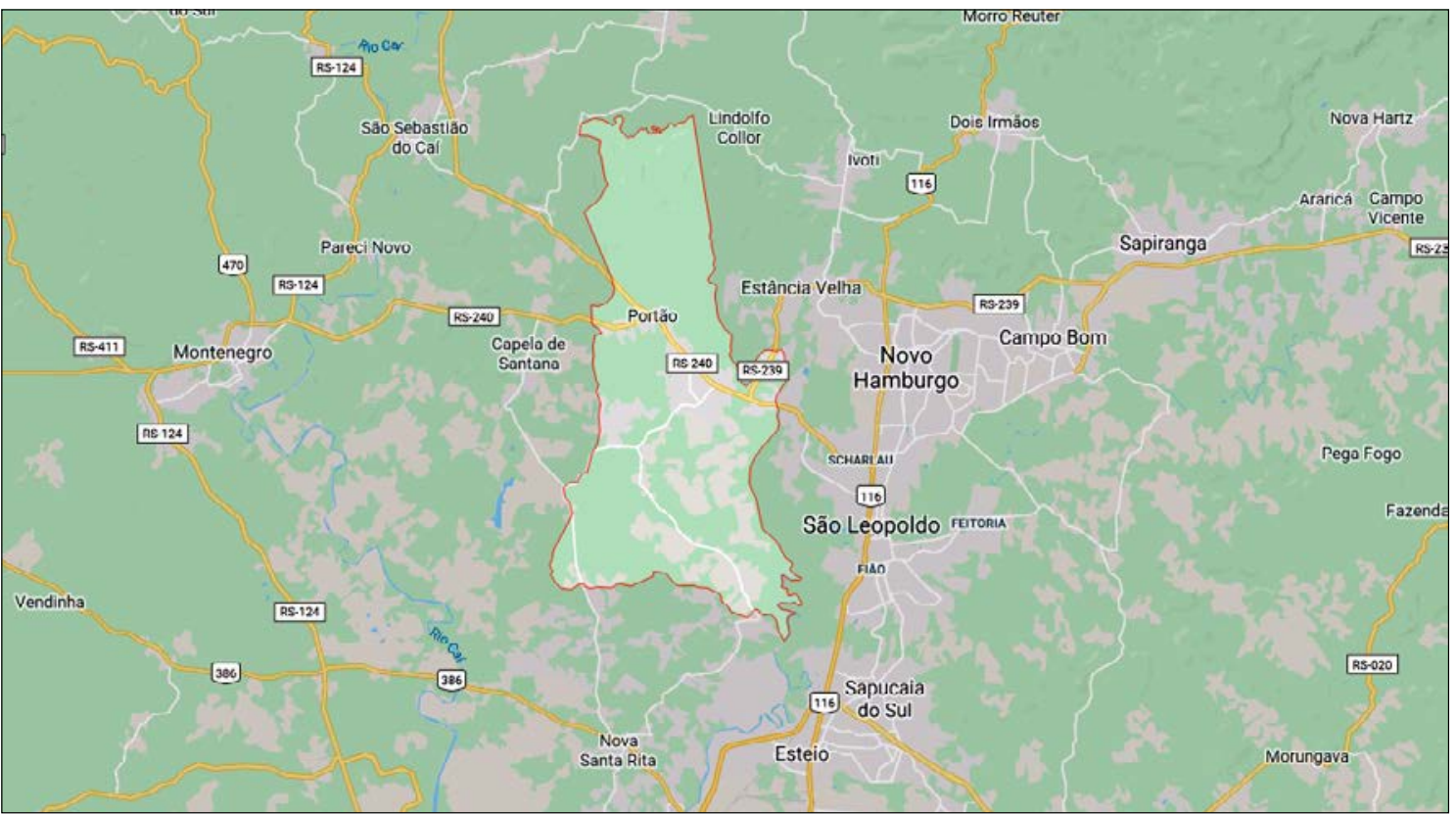

Figura 1 - Mapa do município de Portão. Fonte: https://www.google.com.br/maps. Acesso em: 18 jul. 2020.

2 A região onde hoje está o município de Portão pertencia a São Leopoldo, na época, emancipando-se apenas no século XX. 
2015, em processo de regularização fundiária junto ao INCRA.

O quilombo teve origem na época da escravidão, quando um pequeno grupo de cativos fugiu de fazendas da região e estabeleceu-se num local conhecido como Buraco. Trata-se de uma área rebaixada ao lado de um paredão de pedra, que forma uma espécie de cânion. A descida até o local é acidentada, acarretando dificuldade de acesso, o que se traduziu em segurança e isolamento para os primeiros quilombolas. As pessoas mais velhas dizem que, mesmo após a abolição da escravatura, em 1888, os moradores do Buraco ainda permaneceram lá por mais algum tempo até que acreditassem nas notícias que circulavam sobre a liberdade jurídica. Aos poucos, foram subindo em direção à localidade Morro do Macaco Branco, onde hoje está a família Caetano, uma das descendentes dos fundadores do quilombo.

Inicialmente, famílias negras de outras regiões estabeleceram moradia no quilombo, em aliança com os primeiros moradores. No período pósabolição, configuraram-se cinco famílias, que formaram os troncos antigos da comunidade e foram comprando as terras que compõem o território quilombola, não havendo doação, como é comum na história de muitas comunidades. Uma vez que se estabilizou a comunidade, com as cinco famílias iniciais, seguiu existindo um isolamento, pois não havia outras comunidades quilombolas nos arredores com quem pudessem se relacionar. Há relato de contatos com os bugres/indígenas, mas a relação com os brancos seguiu sendo pouco amigável por um tempo. Ao narrar os festejos que aconteciam nos arredores, os mais velhos contam que inicialmente havia dois salões de baile, um para os negros e outro para os brancos, e a separação era completa: um grupo não podia participar das festas do outro.

Mais tarde, surgiu o baile da corda, presente na história de muitas comunidades remanescentes de quilombos. O início das relações entre brancos e negros começa ainda com uma segregação, numa festa criada com o objetivo de diluir as fronteiras, mas que não suporta a paridade entre os públicos. O baile tornou-se aberto a todos, mas no meio do salão havia uma corda: brancos ficavam de um lado e negros do outro. Com o tempo, a corda foi superada e, então, as danças puderam se dar entre quilombolas e alemães. Estes últimos se constituíam na principal relação do quilombo com a comunidade branca.

Portão é um município que recebeu colonização de imigrantes alemães e contou com mão de obra escrava em fazendas com plantações de milho, feijão e algodão, além de criação de gado. Destas fazendas, os negros fugiram para o Buraco e, depois da abolição, voltaram e compraram as terras com 
o rendimento dos seus trabalhos. A convivência, ora antagônica, ora pacífica, com os alemães está presente na história da comunidade.

O próprio nome da comunidade abre a possibilidade de olhar para as relações raciais. Não deixa de causar curiosidade a presença da palavra "branco" no nome. Não por acaso, falamos aqui de um território entrecruzado com terras ocupadas por descendentes de imigrantes alemães. Uma das versões para a origem do nome se refere aos bugios que povoam a região. Contam que antigamente havia também macacos brancos (os bugios albinos, que são bem raros), que inspiraram o nome da comunidade. Dona Silvina conta que seu avô, João Oliveira, viveu escondido no Buraco e, quando saiu, o primeiro macaco que viu era branco. Daí surgiu o nome.

Há outra versão segundo a qual foi uma brincadeira com os brancos, que chamavam os primeiros moradores da comunidade de macacos. Os negros fizeram uma troça e chamaram a comunidade de Macaco Branco: "Querem nos chamar de macacos? Ora, macacos são vocês!”. Depois de mais de século da nomeação, fica difícil localizar a origem precisa, mas esta versão satírica nos fala de duas coisas: do racismo e do bom humor que circula na comunidade. Claudiomiro Flores diz que o povo ri até em velório, conta piada. É uma forma de levar a vida, que continua com alegria.
Mas esta postura alegre sofre discriminação:

A gente chega faceiro nos lugares, e
as pessoas ficam olhando. Os pretos
são faceiros, a vida é difícil, mas
fazer o que? A gente tem que rir,
mas os brancos ficam nos olhando
estranho... Nós que somos pobres
levamos a vida com alegria, e eles
que têm tudo ficam tristes nos cantos
(Claudiomiro Flores, comunicação
pessoal, 2018).

Expressar alegria e irreverência num contexto racista, com privações no plano material e simbólico, em meio à rejeição à própria existência negra, é uma demonstração de força, resistência e sabedoria. Foi esta obstinação que viabilizou que os quilombolas se mantivessem vivos apesar da escravidão, e que continuem recriando suas vidas em meio a todas as barreiras contemporâneas. Há uma consciência profunda de que existe alguma coisa errada com o sistema, e não com eles, que se demonstra na fala de Claudio. Como diz Maria Firmina dos Reis (2018 [1859]), a mente ninguém pode escravizar.

\section{RELAÇÕES RACIAIS NO TERRITÓRIO}

Em meio aos conflitos raciais, a comunidade não assume posturas hostis em relação aos brancos. Há muitos casamentos inter-raciais, e a fronteira que delimita quem é quilombola não é facilmente identificável. A imagem do quilombo não corresponde a uma comunidade negra ilhada. 
Foi assim em sua origem, quando esteve apartada de qualquer relação com a população branca, e o contexto atual é herdeiro deste momento fundador, mas passou por transformações históricas ao longo de mais de um século. Aos poucos, percebe-se que faz parte da comunidade quem vive dentro das famílias quilombolas e tem uma experiência espacial negra (Pires \& Dobal 2017), ainda que haja variações na cor da pele.

Mesmo havendo relações inter-raciais, segue existindo um contexto de supremacia racial em que uma ideologia racista perpassa todos. Não há uma miscigenação no sentido defendido por Gilberto Freyre (2003), no livro "Casa-grande \& senzala", quando os antagonismos são diluídos, mas sim uma convivência entre as raças que não supera o racismo. As pessoas que entram para a comunidade pelo casamento passam a ter uma experiência quilombola, podendo sofrer discriminação da família de origem, em razão do vínculo com as pessoas negras. Também algumas crianças que nascem destas uniões sofrem com o racismo, sendo mais ou menos desejadas pelas famílias brancas, de acordo com os traços físicos.

O meu entendimento de que quilombolas eram quilombolas, mesmo que as expressões fenotípicas variassem, se aprofundou nos momentos que vivi na companhia deles fora da comunidade. As linhas divisórias oferecem riscos, e um primeiro olhar pode passar longe de capturar as diversas forças que compõem um ser. A territorialidade quilombola se produz na relação com o território, e produz uma forma de relação com o ambiente que se expressa nos corpos, mesmo quando estes deixam o seu lugar de origem.

Esta forma de se territorializar mostrou-se em Yasmim, uma menina de dois anos que acompanhei em consultas médicas, na cidade de Porto Alegre, a pedido de sua mãe, Jenifer. Na primeira vez em que as encontrei, na sala de espera de um hospital, fui barrada por um segurança na porta. Expliquei que procurava uma moça com uma criança. Ele fez um sinal afirmativo com a cabeça e um gesto com a mão, apontando para o chão, na entrada da sala. Achei estranho ele ter apontado tão diretamente para baixo, mas quando as encontrei fez todo o sentido. Jenifer estava sentada numa cadeira, enquanto Yasmim estava no chão, junto com brinquedos, com a mochila, com a bolsa da mãe e com o bebê-conforto, que tinham trazido da viagem com o carro da Secretaria Municipal de Saúde de Portão, que fazia o deslocamento para os hospitais. Yasmim estava acampada no chão do hospital, e a imagem contrastava com as demais crianças do lugar, quietas em suas cadeiras, solitárias, esperando pelo atendimento. O corpo de Yasmim falava do lugar de onde ela vinha, da relação que vive com o território na sua 
comunidade, onde as crianças de modo algum se separam do ambiente, mas crescem em contínua e profunda relação com os espaços que habitam.

Outra experiência em que se expressou a territorialidade quilombola foi uma reunião da comunidade com o prefeito do município de Portão. A pauta era a solicitação de que a prefeitura fizesse o aplainamento dos terrenos onde seriam construídas as casas que a comunidade conquistou no programa "Minha Casa Minha Vida Rural". Foram em grupo e até foi preciso trazer cadeiras de outros lugares, pois a sala de reuniões do prefeito não estava preparada para receber tanta gente. O Índio, presidente da associação quilombola, foi logo dizendo que, na primeira vez que construíram as casas (este seria o segundo lote do programa), a prefeitura resistira em ceder aos pedidos da comunidade: "Agora, fizemos questão de reunir mais gente da comunidade para dar mais força ao pedido”. A estratégia de reunir um coro de vozes para se fazerem ouvir, assim como a alegria que souberam manter naquele ambiente extremamente formal davam a dimensão de seu pertencimento. Naquele momento, não havia dúvidas de que eram quilombolas, e mesmo as peles mais claras se faziam negras, em contraste com a branquitude da elite política de um município de colonização alemã.

A necessidade de organização de uma coletividade para dialogar com a estrutura estatal deixa pistas da dificuldade relacionada ao trânsito dos quilombolas nas dependências de instituições erigidas para a circulação do sujeito homem-branco-cristão-ocidental (Segato 2012). Há um abismo entre a população quilombola e o aparato estatal, sustentado sobre o racismo fundante da modernidade. As demandas burocráticas individuais acabam muitas vezes sendo encaminhadas através de assessorias de políticos do município, que fazem o intermédio com o aparato institucional e reduzem o encontro assimétrico com o racismo das instituições. Os moradores relatam episódios em que entraram em contato direto com órgãos públicos e, a cada vez que se deslocavam até a cidade, os servidores pediam mais documentos e, quando voltavam com estes, outros eram então solicitados, e assim sucessivamente, de modo que simplesmente não conseguiram acessar seus direitos. Num contexto de racismo, não há trânsito seguro no Estado.

A questão da utilização do trator da prefeitura para lavrar a terra é emblemática. Um morador conta que a prefeitura se recusa a passar o trator, alegando que o solo da comunidade tem muita pedra e vai estragá-lo. O jeito, então, é pagar: "pagando, o mesmo trator passa nas nossas terras. Como pode isso?”. O problema são as pedras mesmo? A solicitação da retroescavadeira feita em grupo, para que houvesse o aplainamento da 
terra, dá a dimensão da dificuldade de contar com o apoio do poder institucionalizado.

Por muito tempo, a negação dos serviços públicos à comunidade foi completa. Quando surgiu o programa "Minha Casa Minha Vida Rural”, em um dos primeiros movimentos de diálogo entre uma política pública do Estado e a comunidade, muitas pessoas tiveram receio de levar a imensa documentação exigida, e acabaram não conseguindo acessar este direito, o que demonstra a profunda falha do Estado, ao longo de séculos, em contatar a comunidade e fazer-se confiável. A ausência do Estado era tão grande que o surgimento de uma política pública que pudesse trazer benefícios foi recebida com reserva e incredulidade por algumas pessoas.

Naquele momento em que os contatos com o Estado começavam a acontecer, iniciou-se a produção do já mencionado relatório antropológico do INCRA, em 2015, e havia uma grande ansiedade na equipe para conversar com as idosas da comunidade, que seriam as principais fontes históricas. Entretanto, de modo algum era possível conversar com elas sem que as famílias estivessem presentes. Havia uma mútua desconfiança. Ao mesmo tempo em que a equipe achava que as famílias queriam impedir que elas contassem alguma coisa, os familiares desconfiavam destes corpos estranhos que circulavam pela comunidade.
É possível compreender o que se passou naquele momento, quando localizamos a resistência das famílias em uma prática de cuidado com as pessoas mais velhas. Do mesmo modo que as gerações mais antigas são valorizadas na produção do relatório, elas são valorizadas dentro da comunidade. E, conscientes do racismo que perpassa as relações com o Estado, suas famílias de modo algum deixariam que elas ficassem sozinhas em presença de um grupo, afinal, desconhecido.

O racismo, entretanto, não se restringe às relações externas. Também dentro do território, os quilombolas enfrentam desafios. Um dos relatos mais veementes veio de Iara:

Aqui eles são racistas. O lugar mais
racista do Brasil é o Macaco Branco.
Não adianta o negro estudar que eles
não dão serviço para o negro. Acham
que o negro serve só para escravo.
Minhas sobrinhas não tiveram vez
para trabalhar nas escolas da região.
"Não queremos saber de negro", foi
o recado (Iara, comunicação pessoal,
2018).

Outro caso lembrado é o de Margarete, merendeira negra de uma escola da região que voluntariamente dava aulas de danças africanas para as crianças. Contam que a direção deu um jeito de a fazer sair da escola. Qualquer tentativa de afirmação da cultura negra é barrada, invisibilizada. O Índio, presidente da associação quilombola, menciona que no centro de Portão tem desfile de 
carnaval, mas a única comunidade quilombola do município não é convidada a participar. No desfile de 7 de setembro, a associação Unidos Venceremos do Macaco Branco, comandada pelos alemães, desfila. A quilombola, não.

A comunidade tem uma relação intrincada com os alemães. Como não há fornecimento de água encanada pelo município, os alemães criaram a associação da água, que faz a distribuição para as casas a partir de duas caixas d'água centrais. Eles disponibilizam o serviço de água também para os quilombolas, que pagam uma taxa. Há uma interação entre as comunidades branca e negra e uma tentativa de integração, que surge no nome da associação: Unidos Venceremos. Mas é preciso refletir sobre as ambiguidades da escolha deste nome. Ao mesmo tempo em que há o movimento de união, há um lugar comum que busca esta união pela dissolução da diferença. Estando todos inseridos no paradigma moderno que racializa os corpos (Gargallo 2012), não é possível produzir um lugar homogêneo onde todos sejam iguais. É preciso olhar para as diferenças e criar espaço para que elas possam se manifestar. Os corpos partem de posições desiguais na sociedade, e qualquer tentativa de criação de um lugar único de enunciação ignora as diferenças e silencia as minorias.

\section{EXPRESSÕES DA LUTA PELO TERRITÓRIO}

Um espaço de afirmação da diferença que fortalece a identidade quilombola surge com a política nacional de reconhecimento das comunidades remanescentes de quilombos. No Macaco Branco, o levantamento histórico que vem sendo feito pelo INCRA indica que o território hoje ocupado pelos quilombolas se refere a menos de um quinto do que foi originalmente de posse dos antepassados dos cinco troncos de famílias que compõem a história do grupo. Sendo muitas vezes utilizada como último recurso para a geração de renda, a venda de partes do território foi acontecendo aos poucos, e pode ser compreendida a partir de um olhar sobre as relações étnico-raciais: em um contexto de supremacia racial, a população negra se depara com condições desiguais de negociação e troca com os arredores. A proteção de qualquer direito por parte do Estado por muito tempo foi nula, dada a total invisibilidade desta população pelo aparato estatal.

As condições de trabalho são precárias até hoje, com muitas ocupações informais sem qualquer proteção pelas leis trabalhistas. Neste contexto, muitas vezes, a venda de terras foi uma forma de gerar o rendimento necessário para as necessidades materiais. A comunidade lembra que, em momentos difíceis, houve quem precisou trocar 
terra por comida. As mulheres também contam que muitas vezes os homens da comunidade venderam pedaços de terra a "preço de banana", em condições de negociação desiguais: alguns compradores interessados nas terras ofereciam bebidas alcoólicas aos quilombolas e faziam suas propostas enquanto eles estavam sob o efeito do álcool, com as condições alteradas para tomada de decisão. Nestas transações, sob aparências de legalidade, a comunidade foi sendo despojada de grande parte do território.

A maior parte das terras que compuseram a comunidade pertence hoje aos alemães e a pessoas que vieram de outras regiões, em busca de um lugar para viver e de áreas para cultivo de eucalipto e acácia-negra com fins comerciais. A silvicultura é uma das principais atividades econômicas na zona rural de Portão e dos municípios vizinhos. Uma parcela importante do território quilombola dos séculos XIX e XX está sendo utilizada na plantação destas espécies exóticas, destinadas à produção de lenha, carvão, madeira e tanino - substância utilizada no tratamento do couro nos cortumes que povoam a região ${ }^{3}$ (Figura 2).

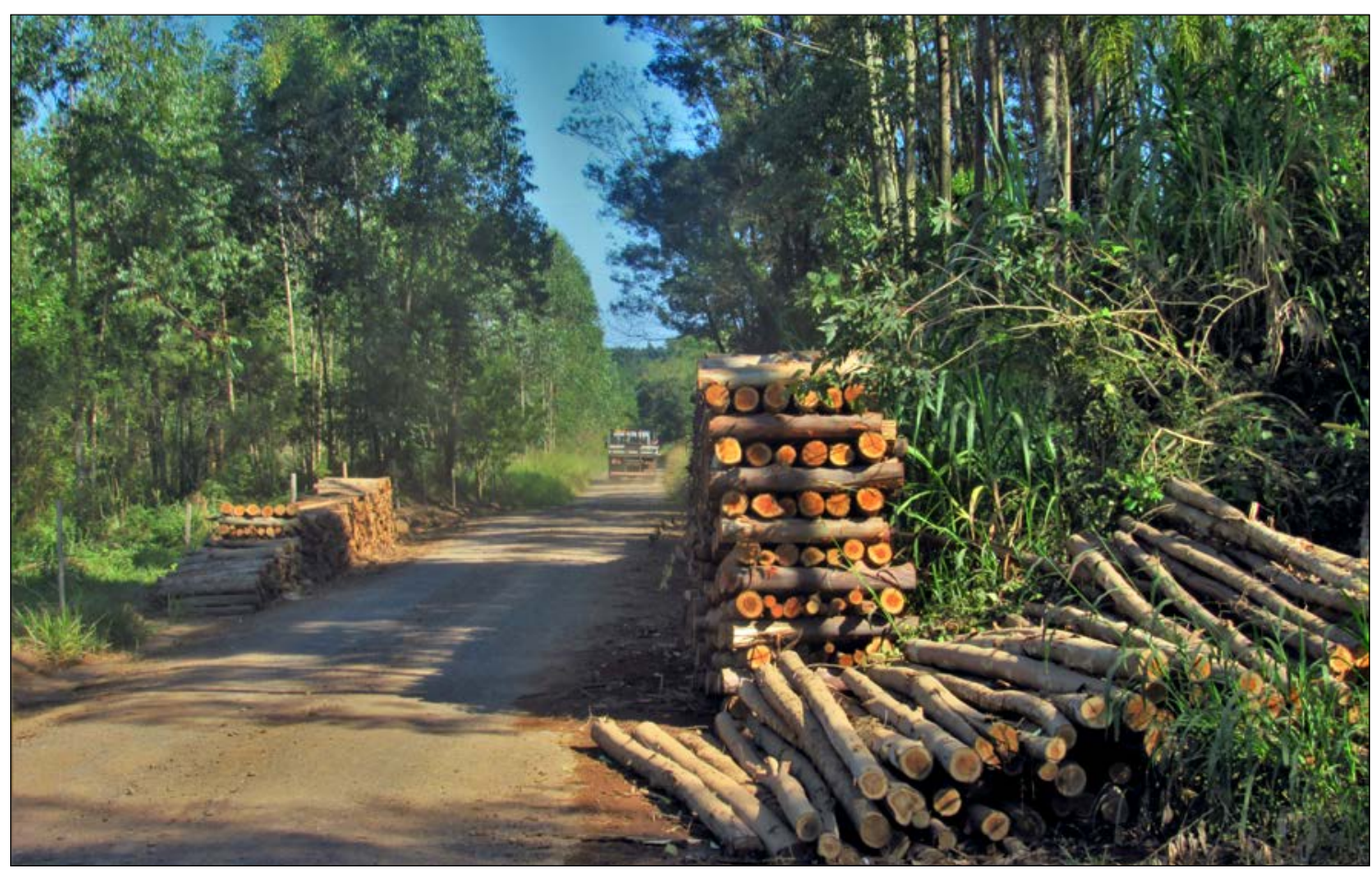

Figura 2 - Estrada da comunidade ladeada por toras de acácia-negra. Foto: Dirce de Christo (2018).

3 Estância Velha, município vizinho de Portão, é conhecida como a capital nacional do couro, figurando como uma das maiores produtoras mundiais. Também outros municípios da região, incluindo Portão, possuem curtumes, regulamentados ou clandestinos, que compõem a cadeia produtiva do couro e se utilizam da produção silvícola de acácia-negra. 
Fato é que muito do território que foi quilombola está hoje sendo explorado por pequenos investidores do ramo silvícola. Mas, de alguma forma, esse território segue fazendo parte da comunidade. Isso porque são homens e mulheres quilombolas que são contratados, informalmente, para trabalhar nessas terras, para cortar o mato, carregar as toras de madeira. A relação com o território, que se faz através dos corpos, segue acontecendo. Os corpos quilombolas têm conhecimento daquele lugar, foram criados naquele território, aprenderam a suportar as intensidades do trabalho sobre aquelas terras.

Por entre as investidas do sistema capitalista moderno-colonial e a busca do lucro através da exploração dos recursos naturais, o quilombo Macaco Branco segue perpetuando sua relação com o território de seus ancestrais. Uma relação que se faz apesar e além das gramáticas coloniais da propriedade privada. Uma relação que se faz no corpo, no conhecimento prático, no movimento, no percorrer cotidiano do território, que carrega a história da comunidade.

Essa composição da relação com o território também evidencia as assimetrias das relações étnico-raciais. Viver sobre um território que foi de seus antepassados sem o possuir formalmente e sem usufruir dos lucros que a exploração da terra produz: este cenário experienciado pela comunidade nos dá dimensão de uma das faces que assume o racismo na contemporaneidade. Longe de uma democracia racial, seguimos convivendo com a exploração do saber e do trabalho negro, em funções que exigem muito da força corporal e não garantem direitos trabalhistas mínimos. Tudo isso somado à expropriação dos territórios negros, que, às vezes, assume aparências de legalidade, mas acontece em condições desiguais de troca econômica e substitui modos tradicionais de relação com o território por iniciativas individuais.

Compreender o território como um conceito que vai além da terra e engloba as relações que se produzem sobre ela (Porto Gonçalves 2006) é um caminho para observar a geografia local. A relação com a terra assume sua forma material nos corpos que ocupam o território e dão concretude a esta interação. As relações desses corpos quilombolas com outros grupos étnico-raciais esbarra nas assimetrias produzidas pelo racismo; a posse de grande parte do território é perdida, mas a relação territorial se mantém e se traduz nos corpos, que seguem a ocupar o território e a trabalhar a partir do conhecimento produzido a partir disso.

A concepção de território de Porto Gonçalves (2002) não separa o social do geográfico, entendendo que as sociedades constroem seus espaços ao mesmo tempo em que produzem territorialidades. Assim, ao olhar para os territórios negros rurais, 
é necessário considerar a dimensão imaterial que se entrelaça à ocupação do espaço físico, pois, como assinala Marcelo Mello, em trabalho realizado com a comunidade quilombola Cambará, a demanda pela terra "[...] não se resume a uma dimensão material ou utilitária. Ela carrega afetos, personagens, subjetividades e marcos estritamente relacionados àquilo que o grupo apresenta como o seu território" (Mello 2012:206). Igualmente, a luta pelo território não se expressa apenas em luta pela terra, mas também no âmbito das relações. Cheguei a essa compreensão ao longo da pesquisa, quando precisei reorganizar meu olhar para dar conta do que a comunidade me apresentava.

Inicialmente, tinha buscado aproximações com a temática territorial olhando para a questão agrária, mas, nos momentos em que passei na comunidade, muitos outros assuntos ganhavam tanta importância quanto a demarcação das terras, o que foi me levando a concluir que havia outras questões urgentes para serem resolvidas, em paralelo à luta pelo território físico. Essa conclusão sofreu um giro de significado quando me dei conta de que não eram "outras" demandas que a comunidade apresentava, mas era a própria questão territorial que assumia formas diversas, que vão além do enfoque agrário.

A política de demarcação de territórios quilombolas produzida pelo INCRA é de grande importância e é uma luta da comunidade, cada vez mais arriscada neste momento em que o candidato eleito à presidência do Brasil declara publicamente que não vai demarcar nenhum centímetro de terra para indígenas e quilombolas ${ }^{4}$. Junto à demanda pela terra, com dimensão político-institucional nas últimas duas décadas, a comunidade enfrenta outras batalhas que se apresentam desde sua origem e se manifestam em diferentes materialidades, como as limitações das possibilidades de trabalho, agravadas com a redução do território - que inviabiliza o autossustento -, e o consequente dano aos corpos, resultante da forte exploração da força de trabalho quilombola e da experiência de vida em um contexto racista que ataca a integridade das pessoas negras de diversas formas.

Os postos de trabalho ocupados pela comunidade são precários. Trabalho no mato, em curtumes e em carvoarias, todos envolvendo grandes esforços físicos ou riscos de contaminação química. Nos matos, fazem o corte de eucalipto e acácia, o carregamento das toras para os caminhões, a retirada a facão da casca da acácia para extração

4 Jair Bolsonaro foi eleito em 28 de outubro de 2018, no segundo turno das eleições presidenciais. O candidato trouxe inúmeras propostas que atacam os direitos de quilombolas e das minorias sociais de modo geral, em uma postura de intolerância à diferença, que tem incentivado ataques aos grupos minoritários em todo o Brasil, como foi o caso do Mestre Capoeirista Moa do Katendê, morto a facadas no dia das eleições, após ter anunciado seu voto em Fernando Haddad, que também disputava as eleições. 
de tanino, utilizado no curtimento de couro. Nas carvoarias, é feito o trabalho nos fornos, com risco envolvendo a inalação de grandes volumes de fumaça. Nos curtumes, é feita a utilização de produtos químicos com altos níveis de toxicidade, os quais são aplicados no couro. Estas formas de trabalho, com acentuado desgaste físico e execução de tarefas perigosas, expõem duramente a condição de comunidade remanescente de quilombo. Mais de um século desde a abolição e os negros seguem tendo sua força de trabalho superexplorada, executando tarefas que colocam seus corpos em constante risco.

Lizete Caetano conta que muitos anos atrás, quando começou a trabalhar num curtume, sofreu um acidente de trabalho logo na primeira semana, quando caiu de uma mesa onde o couro era trabalhado e machucou seriamente um dos joelhos. Como estava em contrato de experiência, teve que trabalhar com o joelho arrebentado durante três meses para não perder o emprego, pois, nesse período inicial, não tinha nenhuma garantia trabalhista, nem mesmo direito a auxíliodoença, em razão do acidente. Em uma pesquisa sobre a cadeia de produção do couro, as primeiras informações que acessei, sem que esse fosse meu objetivo, foram as muitas denúncias ao Ministério do Trabalho sobre as más condições laborais. No entanto, quando falamos de cidades pequenas, onde as opções de emprego são limitadas e a maioria das pessoas se conhece, dificilmente os trabalhadores vão mover ações individualmente contra as empresas. Lizete fala sobre a reduzida possibilidade de escolha quanto ao trabalho na comunidade: "Eu nunca gostei de trabalhar na roça, mas tive que trabalhar. Aqui a gente tem que aprender a fazer de tudo. Não dá uma coisa, faz outra”.

As mulheres também participam do trabalho pesado nas plantações. Gorete de Paula conta que, desde os sete anos de idade, trabalhou no mato, descascando acácia para fazer lenha. Na escola, estudou com quem mais tarde seria seu patrão. Quando engravidou, não teve nenhum benefício que lhe permitisse suspender o trabalho. Com um bebê de 25 dias, já ia descascar a lenha, colocando o bebê num cesto embaixo de uma lona quando chovia. Foi assim com os três filhos que ela teve. Os olhos se encheram de emoção quando ela contou que criou os meninos com muita simplicidade: fazia uma panela de polenta e colocava no chão para eles comerem direto na colher. Hoje, tem muito orgulho dos três, muito trabalhadores e amorosos com a família.

Gorete encarou todos os desafios, lutou com as próprias mãos pelo sustento da vida, mas o peso do trabalho intenso deixa marcas no corpo. Quando a visitei, em fevereiro de 2018, entreguei 
fotos que tinha feito em 2015, na primeira visita à comunidade. Ela demorou a reconhecer-se nas fotografias por causa da visão, que está seriamente comprometida pela diabetes. Muitos são seus problemas de saúde, entre eles artrite e artrose, que têm forte relação com os movimentos repetitivos decorrentes do descascar contínuo das toras de acácia durante muitas horas diariamente, ao longo de anos.

A luta pelo território acontece em muitas frentes no Macaco Branco. Há a luta direta pela restituição do território ancestral, que dá origem a uma segunda luta por condições dignas de trabalho, com garantia de direitos, uma vez que a redução do território impede que o trabalho na própria terra gere o sustento material. E há também a luta pela integridade dos corpos, que é condição para a vida e é atacada insistentemente pelo racismo e pela formatação do sistema trabalhista de origem escravocrata, que vigora na região. $\mathrm{O}$ ataque às terras e a utilização da mão de obra quilombola em regime de superexploração estão intrinsecamente relacionados ao racismo, que deixa a comunidade negra em condições desiguais de relação com o entorno.

\section{CONSIDERAÇ̃̃ES FINAIS}

Como foi possível observar, a ofensiva colonial contra a existência de outros mundos contrastantes com o ideal moderno, que se acredita o único possível, é uma realidade quando olhamos para a comunidade quilombola Macaco Branco. Constituído por negros que se libertaram do cativeiro e inicialmente cultivaram terras inóspitas o suficiente para não serem ocupadas pelos brancos, o quilombo cresceu a partir do trabalho de seus moradores, que possibilitou a compra de áreas maiores e mais apropriadas à agricultura. Não obstante, a história do povo negro que habita o lugar é invisibilizada nas narrativas oficiais, que atribuem aos alemães a construção das riquezas da região, deixando de mencionar todo o trabalho pesado que a população negra executou nesse processo. Aí se mostra a incapacidade do sistema de lidar com a multiplicidade, com as contradições que envolvem a história, buscando uma narrativa linear, que supõe a inexistência de conflitos. Entretanto, os conflitos estão na raiz da sociedade brasileira, constituída sob um paradigma de violência e negação das vidas que não se apresentam à imagem e semelhança da civilização europeia.

Por outro lado, a instauração da luta pela identidade quilombola, que se dá a partir da garantia de direitos constitucionais - já sob intenso ataque de forças que seguem alinhadas ao paradigma da aniquilação -, traz à tona essas diferenças historicamente negadas como forma 
de afirmação política. A luta coletiva por direitos, expressa na reunião com o prefeito de Portão, evidencia a forma de existência coletiva da comunidade, que se diferencia do individualismo moderno e afirma uma ontologia distinta, baseada nas relações entre as pessoas e o território.

$\mathrm{Na}$ comunidade quilombola Macaco Branco, o abismo entre natureza e sociedade almejado pela modernidade não se completa. No cotidiano, há um modo de reproduzir a vida em conexão com o território, que persiste nas margens e nos interstícios da modernidade colonial. A existência coletiva sinaliza a resistência ao individualismo, que isola os sujeitos da comunidade e do lugar habitado. Num ritmo de vida que comporta a alegria do cotidiano, revela-se a força de uma comunidade que há séculos enfrenta a violência colonial e resiste ao processo de abandono do meio rural. A ancestralidade segue re-existindo nos corpos das novas gerações, que recriam constantemente as possibilidades da vida, das diversas formas de vida que habitam o território.

Entretanto, a reprodução do modo de vida quilombola no Macaco Branco se encontra sob risco, como vem acontecendo com comunidades tradicionais de todo o país. O avanço do capital sobre as terras tradicionais, que neste momento ocorre em grande intensidade sobre a região amazônica, atinge fortemente a região Sul do Brasil desde o século passado, e as comunidades quilombolas se encontram com territórios reduzidos, que dificultam sua autonomia histórica no sustento da vida, transformando os moradores em mão de obra barata para um mercado de trabalho racista e explorador

Os riscos se intensificam neste momento em que vivemos o recrudescimento dos ataques às comunidades rurais no Brasil, ao mesmo tempo em que o projeto capitalista exibe seus limites com a crise socioambiental que se intensifica e, ainda que as possibilidades de resposta sejam assimétricas entre os sujeitos, todos estão sendo afetados. Entretanto, para quem segue acreditando na potência humana neste tempo em que explodem as preocupações quanto à concepção moderna de sociedade, as experiências do viver quilombola deixam pistas de como reinventar a vida. A observação dos processos de resistência das comunidades quilombolas traz potenciais para a busca de possibilidades de relações que ofereçam alternativas à modernidade e à sua produção de desigualdade e exclusão.

A descrição etnográfica da comunidade contribui para o debate sobre as comunidades quilombolas no Brasil e também aporta dados às narrativas, ainda escassas, sobre a presença das comunidades negras na formação do território gaúcho. No entanto, o alcance da pesquisa se limita a apenas uma comunidade e sua realização se deu 
no tempo de um mestrado, o que deixa espaço para pesquisas mais aprofundadas, que possam trazer à tona aspectos ignorados neste trabalho inicial. Ao mesmo tempo, as observações feitas até aqui também indicam caminhos para novas investigações.

Ao compreendermos que, mesmo em uma região majoritariamente branca, o quilombo consegue recriar uma forma de existência baseada na coletividade e numa relação profunda com o território, surge potencial para a continuidade dessa pesquisa e para outros estudos com comunidades tradicionais que tragam possibilidades ontológicas múltiplas para a discussão. A pergunta que colocamos é: como se recria essa forma de vida?
Em recente dissertação de mestrado (Christo 2018), nosso olhar se concentrou sobre as práticas das mulheres, que são as principais agentes no cuidado e na reprodução das vidas que conformam o território. Mas, ao fazer essa pergunta e olhar para os sujeitos envolvidos, é possível perceber que o modo de existência em questão é lapidado desde o início das vidas que povoam a comunidade, desde a infância. Assim, um próximo passo da investigação poderia se dar a partir do olhar sobre as crianças, buscando entender o que há de específico na experiência da infância e no educar quilombola a constituir esses sujeitos que defendem um modo de vida em conexão com o território e com os seres que o habitam.

\section{REFERÊNCIAS}

Almeida, A. W. B. 2008. Terras tradicionalmente ocupadas: processos de territorialização, movimentos sociais e uso comum, in Terra de quilombo, terras indígenas, "babaçuais libres", "castanhais do povo", faxinais e fundos de pasto: terras tradicionalmente ocupadas. 2. ed.Editado por A. W. B. Almeida, pp. 25-131. Manaus: PGSCA-UFAM.

Anjos, J. C. G. 2004. Apresentação, in São Miguel e Rincão dos Martimianos: ancestralidade negra e direitos territoriais. Organizado por J. C. G. Anjos e S. B. Silva, pp. 13-17. Porto Alegre: Editora da UFRGS.

Brasil. 2003. Presidência da República. Decreto $n^{\circ}$. 4887, de 20 de novembro de 2003. Regulamenta o procedimento para identificação, reconhecimento, delimitação, demarcação e titulação das terras ocupadas por remanescentes das comunidades dos quilombos de que trata o art. 68 do Ato das Disposições Constitucionais Transitórias. Brasília, DF. Disponível em: http://www.planalto.gov.br/ ccivil_03/decreto/2003/d4887.htm. Acesso em: 03 out. 2019. 
Brasil. 2007. Presidência da República. Decreto n 6040, de 7 de fevereiro de 2007. Política Nacional de Desenvolvimento Sustentável dos Povos e Comunidades Tradicionais. Brasília, DF. Disponível em: http://www.planalto.gov.br/ccivil_03/_ato2007-2010/2007/decreto/d6040.htm. Acesso em: 04 ago. 2018.

Brustolin, C. 2015. Reconhecimento e desconsideração: a regularização fundiária dos territórios quilombolas sob suspeita. São Luís: Café e Lápis/EDUFMA.

Cardoso, R. R. S. 2007. Capítulos de formação de um território negro rural: escravidão no Vale do Rio Caí/RS (1870-1888). Revista Mouseion 1:26-30. Disponível em: https://revistas.unilasalle.edu.br/ documentos/Mouseion/Vol1/vol1jun2007p26_30.pdf. Acesso em: 15 jul. 2020.

Christo, D. C. 2018. As vidas que as mulheres criam: caminhos de resistência e luta pelo território na comunidade quilombola Macaco Branco. Dissertação de Mestrado, Faculdade de Ciências Econômicas, Programa de Pós-Graduação em Desenvolvimento Rural, Universidade Federal do Rio Grande do Sul, Porto Alegre.

Dimppir. 2009. Caminhos da Feitoria do Linho Cânhamo - A trajetória histórica do povo negro em São Leopoldo. Disponível em: https://www.youtube.com/watch?v=kRR1eTqlPiU. Acesso em: 17 jul. 2020.

Escobar, A. 2015. Territorios de diferencia: la ontología política de los "derechos al territorio". Cuadernos de Antropología Social 41:25-38.

Freyre, G. 2003. Casa-grande \& senzala. 48. ed. São Paulo: Global.

Gargallo, F. 2012. Feminismos desde Abya Yala. Entrevista a Francesca Gargallo. Disponível em: https:// www.youtube.com/watch?v=MSCZm5brTh8. Acesso em: 26 out. 2018.

Latour, B. 1994. Jamais fomos modernos: ensaio de antropologia simétrica. Rio de Janeiro: Editora 34. 
Mello, M. M. 2012. Reminiscências dos quilombos: territórios da memória em uma comunidade negra rural. São Paulo: Terceiro Nome.

Montenegro, J. 2012. Povos e comunidades tradicionais, desenvolvimento e decolonialidade: articulando um discurso fragmentado. Okara: Geografia em Debate 6(1):163-174.

Pires, C. L. Z., e W. L. M. Dobal. 2017. O tambor e o território na educação escolar quilombola. Terr@ Plural 11(1):93-107.

Porto Gonçalves, C. W. 2002. Da Geografia às Geo-grafias: um mundo em busca de novas territorialidades, in La guerra infinita: hegemonía y terror mundial. Editado por A. E. Ceceña e E. Sader, pp. 217-256. Buenos Aires: CLACSO.

Porto Gonçalves, C. W. 2006. A geograficidade do social: uma contribuição para o debate metodológico para os estudos de conflitos e movimentos sociais na América Latina. Revista Eletrônica da Associação dos Geógrafos Brasileiros 1(2):5-26. Disponível em: http://seer.ufms.br/index.php/RevAGB/article/ view/1344/859. Acesso em: 05 out. 2018.

Reis, M. F. 2018 [1859]. Úrsula. Porto Alegre: Taverna.

Santilli, J. 2002. A biodiversidade e as comunidades tradicionais. Disponível em: http://arquivos.ambiente. sp.gov.br/cea/2011/12/JulianaS.3.pdf. Acesso em: 03 out. 2018.

Segato, R. L. 2012. Gênero e colonialidade: em busca de chaves de leitura e de um vocabulário estratégico descolonial. e-cadernos CES (18):106-131. DOI: https://doi.org/10.4000/eces.1533

Silva, S. B., e I. C. Bittencourt Junior. 2004. Etnicidade e territorialidade: o quadro teórico, in São Miguel e Rincão dos Martimianos: ancestralidade negra e direitos territoriais. Organizado por J. C. G. Anjos e S. B. Silva, pp. 21-29. Porto Alegre: Editora da UFRGS. 